\title{
Inhibitory Effects of Cucurbitane-Type Triterpenoids from Momordica charantia Fruit on Lipopolysaccharide-Stimulated Pro-Inflammatory Cytokine Production in Bone Marrow-Derived Dendritic Cells
}

\author{
Thao Quyen Cao ${ }^{1,2,+}$, Nguyen Viet Phong ${ }^{3,+}{ }^{+}$Jang Hoon Kim ${ }^{4,+} \mathbb{C}$, Dan Gao ${ }^{5}$, Hoang Le Tuan Anh ${ }^{6}$, \\ Viet-Duc Ngo ${ }^{6}$, Le Ba Vinh ${ }^{3,5}$, Young Sang Koh ${ }^{7}(\mathbb{1})$ and Seo Young Yang ${ }^{8, *(1)}$
}

1 Drug Research and Development Center, College of Pharmacy, Daegu Catholic University, Gyeongsan-si 38430, Korea; caothaoquyen@tdtu.edu.vn

2 Institute of Pharmaceutical Research and Development, College of Pharmacy, Wonkwang University, Iksan 54538, Korea

3 Institute of Marine Biochemistry (IMBC), Vietnam Academy of Science and Technology (VAST), Hanoi 100000, Vietnam; ngvietphong@gmail.com (N.V.P.); vinhrooney@gmail.com (L.B.V.)

4 Department of Herbal Crop Research, National Institute of Horticultural and Herbal Science, RDA, Eumseon 27709, Korea; oasis5325@gmail.com

check for updates

Citation: Cao, T.Q.; Phong, N.V.; Kim, J.H.; Gao, D.; Anh, H.L.T.; Ngo, V.-D.; Vinh, L.B.; Koh, Y.S.; Yang, S.Y. Inhibitory Effects of

Cucurbitane-Type Triterpenoids from Momordica charantia Fruit on

Lipopolysaccharide-Stimulated Pro-Inflammatory Cytokine Production in Bone Marrow-Derived Dendritic Cells. Molecules 2021, 26, 4444. https://doi.org/10.3390/ molecules26154444

Academic Editor: Silvie Rimpelová

Received: 8 June 2021

Accepted: 20 July 2021

Published: 23 July 2021

Publisher's Note: MDPI stays neutral with regard to jurisdictional claims in published maps and institutional affiliations.

Copyright: (C) 2021 by the authors. Licensee MDPI, Basel, Switzerland. This article is an open access article distributed under the terms and conditions of the Creative Commons Attribution (CC BY) license (https:/ / creativecommons.org/licenses/by/ $4.0 /)$.
5 College of Pharmacy, Chungnam National University, Daejeon 34134, Korea; dangao@gmail.com

6 Center for Research and Technology Transfer, VAST, Hanoi 100000, Vietnam; hoangletuananh@hotmail.com (H.L.T.A.); ngovietduc@tdt.edu.vn (V.-D.N.)

7 Department of Medicine, School of Medicine, Jeju National University, 102 Jejudaehakno, Jeju 63243, Korea; yskoh7@jejunu.ac.kr

8 Department of Pharmaceutical Engineering, Sangji University, Wonju 26339, Korea

* Correspondence: syyang@sangji.ac.kr; Tel./Fax: +82-33-738-7652

+ These authors contributed equally to this work.

Abstract: The bitter melon, Momordica charantia L., was once an important food and medicinal herb. Various studies have focused on the potential treatment of stomach disease with $M$. charantia and on its anti-diabetic properties. However, very little is known about the specific compounds responsible for its anti-inflammatory activities. In addition, the in vitro inhibitory effect of $M$. charantia on pro-inflammatory cytokine production by lipopolysaccharide (LPS)-stimulated bone marrow-derived dendritic cells (BMDCs) has not been reported. Phytochemical investigation of $M$. charantia fruit led to the isolation of 15 compounds (1-15). Their chemical structures were elucidated spectroscopically (one- and two-dimensional nuclear magnetic resonance) and with electrospray ionization mass spectrometry. The anti-inflammatory effects of the isolated compounds were evaluated by measuring the production of the pro-inflammatory cytokines interleukin IL-6, IL-12 p40, and tumor necrosis factor $\alpha$ (TNF- $\alpha$ ) in LPS-stimulated BMDCs. The cucurbitanes were potent inhibitors of the cytokines TNF- $\alpha$, IL-6, and IL-12 p40, indicating promising anti-inflammatory effects. Based on these studies and in silico simulations, we determined that the ligand likely docked in the receptors. These results suggest that cucurbitanes from $M$. charantia are potential candidates for treating inflammatory diseases.

Keywords: Momordica charantia; bioactive compound; anti-inflammatory effect; triterpenoid

\section{Introduction}

Inflammation is a beneficial host response to an external challenge or cellular injury that leads to the release of inflammatory mediators, finalizing the restoration of tissue function and structure [1]. Once activated, inflammatory cells secrete increased amounts of nitric oxide (NO), prostaglandin $\mathrm{E}_{2}$, and cytokines (e.g., interleukin (IL)-1 $\beta$, IL-6, IL12 , and tumor necrosis factor- $\alpha(\mathrm{TNF}-\alpha))$ to initiate the inflammatory process. These 
pro-inflammatory mediators can also serve as targets to disrupt this mechanism therapeutically [2]. Inflammation is subclassified into acute and chronic inflammation. Acute inflammation is a rapid response in the early stage of inflammation that typically lasts from minutes to a few days. It is usually beneficial for the host to initiate healing and promote tissue recovery. Once acute inflammation fails to resolve the damage, inflammation will progress to the chronic stage-a low-grade inflammation that persists for weeks, months, or even years [3]. The World Health Organization (WHO) ranks chronic diseases as the greatest threat to human health. Chronic inflammation is related to many human diseases, including diabetes, rheumatoid arthritis, atherosclerosis, asthma, neurodegenerative disorders, and cancer [3,4].

Natural products are rich sources for drug discovery, and the development of active components from medicinal herbs continues to be an important source of therapeutic agents for chronic inflammation [5]. The bitter gourd (Momordica charantia L.) belongs to the family Cucurbitaceae and has long been used in foods and medicines [6]. Bitter gourd possess anti-diabetic [6], anti-inflammation [7], anti-oxidant [8], anti-viral [8], anticancer [9], and anti-hyperlipidemic [10] effects. Phytochemical investigations revealed that cucurbitane-type triterpenes are the major subclass of compounds in M. charantia [7,9], and more than 270 cucurbitane-type triterpenoids have been isolated from plant organs with various pharmaceutical effects [11-14]. For instance, xuedanencins $\mathrm{G}$ and $\mathrm{H}$ isolated from the tubers of Hemsleya penxianensis were cytotoxic with $\mathrm{IC}_{50}$ values of 1.82 and 2.45 $\mu \mathrm{M}$, respectively [14]. Cucurbitacin B isolated from Hemsleya endecaphylla had potent anti-HIV-1 effects in C8166 cells (EC $=0.09 \mu \mathrm{g} / \mathrm{mL}$ ), with a selectivity index of 16.7 [15]. Cucurbitane-type triterpenoids from $M$. charantia reduced NO production with $\mathrm{IC}_{50}$ values of 11.3-29.1 $\mu \mathrm{M}$ [16].

Our continued efforts to study biologically active compounds isolated from medicinal herbs led to the isolation of 15 cucurbitane-type terpenoids (1-15) from M. charantia fruit. Here, we report the isolation, structure elucidation, and in vitro and in silico antiinflammatory activities of the isolated metabolites in lipopolysaccharide (LPS)-stimulated bone marrow-derived dendritic cells (BMDCs).

\section{Results and Discussion}

To characterize the bioactive metabolites responsible for the anti-inflammatory effects, efficient chromatographic separation techniques enabled the isolation of $15 \mathrm{com}$ pounds (1-15) from M. charantia. (Figure 1), which were identified as 3,7,25-trimethoxycucurbita5,23(E)-dien,19-al (1) [17], goyaglycoside-d (2) [18], momordicoside G (3) [19], karaviloside II (4) [20], goyaglycoside-b (5) [18], momordicoside $\mathrm{F}_{2}(\mathbf{6})$ [19], 3-[(5-formyl-7ß-hydroxy-25-methoxycucurbita-5,23dien-3-yl)oxy]-3-oxopropanoic acid (7) [21], 3-[(25-O-methylkaravilagenin D-3-yl)oxy]-2-oxoacetic acid (8) [21], 73,25-dimethoxycucurbita-5(6),23(E)-dien-19-al 3-O- $\beta$-D-allopyranoside (9) [22], 3-[(5-formyl-7 $\beta$ methoxy-7,23S-dimethoxycucurbita-5,23-dien-3-yl)oxy]-3-oxopropanoic acid (10) [21], (19R,23E)-5ß,19-

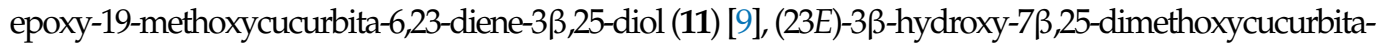
5,23-dien-19-al (12) [17], 3ß,7ß,25-trihydroxycucurbita-5,23(E)-dien-19-al (13) [17], 3-[(5-formyl-7ß,25dihydroxymethoxycucurbita-5,23-dien-3-yl)oxy]-3-oxopropanoic acid (14) [21], and 19S, 25-dimethoxy5,23-dien-5 3,19 -epoxycucurbitane-3-O- $\beta$-allopyranoside (15) [18], by comparison of their spectral data with values reported in the literature.

Compound 1 was obtained as a white amorphous powder, with $[\alpha]_{\mathrm{D}}{ }^{20}=-77.8$ $(c=0.2, \mathrm{MeOH})$. The infrared (IR) spectrum of 1 showed strong absorption by hydroxyl $\left(3398 \mathrm{~cm}^{-1}\right)$ and ketone $\left(1730 \mathrm{~cm}^{-1}\right)$ groups, and a distinctive absorption band for an olefinic group $\left(1066 \mathrm{~cm}^{-1}\right)$. Using high-resolution electrospray ionization mass spectrometry (HR-ESI-MS), the molecular formula was determined to be $\mathrm{C}_{33} \mathrm{H}_{54} \mathrm{O}_{4}$ from the positive-ion $[\mathrm{M}+\mathrm{Na}]^{+}$at $m / z$ 537.3918. To our knowledge, this is the first report of the nuclear magnetic resonance (NMR) assignment of this compound. The NMR spectra of 1 indicated a triterpenoid, one of the major components of $M$. charantia. The ${ }^{1} \mathrm{H}-\mathrm{NMR}$ spectrum of 1 showed seven tertiary methyl groups at $\delta_{\mathrm{H}} 1.07,1.15,1.25,1.43$, and $1.50(\mathrm{~s}$, $3 \mathrm{H})$ and $1.56(\mathrm{~s}, 6 \mathrm{H})$; three proton resonances at $\delta_{\mathrm{H}} 5.71(\mathrm{br} \mathrm{m}, \mathrm{H}-23$ and $\mathrm{H}-24)$ and $6.26(\mathrm{~d}$, 
$J=4.8 \mathrm{~Hz}, \mathrm{H}-6)$; and three methoxy groups at $\delta_{\mathrm{H}} 3.58(\mathrm{~s}, 3 \mathrm{H}, \mathrm{H}-3)$ and $3.45(\mathrm{~s}, 6 \mathrm{H}, \mathrm{H}-7$ and $\mathrm{H}-25)$. The ${ }^{13} \mathrm{C}-\mathrm{NMR}$ spectrum together with the HMQC data showed 33 carbon signals, four olefinic carbons $\left(\delta_{\mathrm{C}} 146.1, \mathrm{C}-5 ; 124.5, \mathrm{C}-6\right.$; $128.5 \mathrm{C}-23$; and 137.1, C-24), and one ketone $\left(\delta_{\mathrm{C}} 208.0, \mathrm{C}-19\right)$, including three methoxy at $\delta_{\mathrm{C}} 56.1,51.2$, and 50.3. The NMR data of 1 were very similar to those of $3 \beta, 7 \beta, 25$-trihydroxycucurbita-5,23(E)-dien-19-al, except for the presence of three methoxy groups at C-3, C-7, and C-25 [17]. Detailed analyses of the ${ }^{1} \mathrm{H}-{ }^{1} \mathrm{H}$ COSY, HMQC, and HMBC data confirmed the planar structure of $\mathbf{1}$, which was identified as 3,7,25-trimethoxycucurbita-5,23(E)-dien,19-al. Previously, compound $\mathbf{1}$ has been produced by the methanolysis reaction [17].

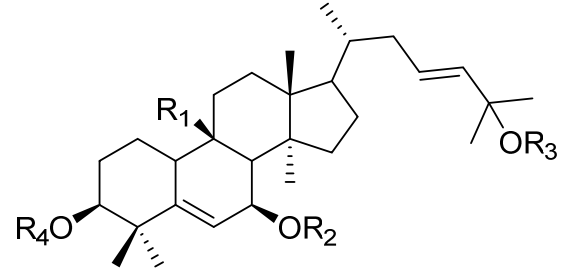

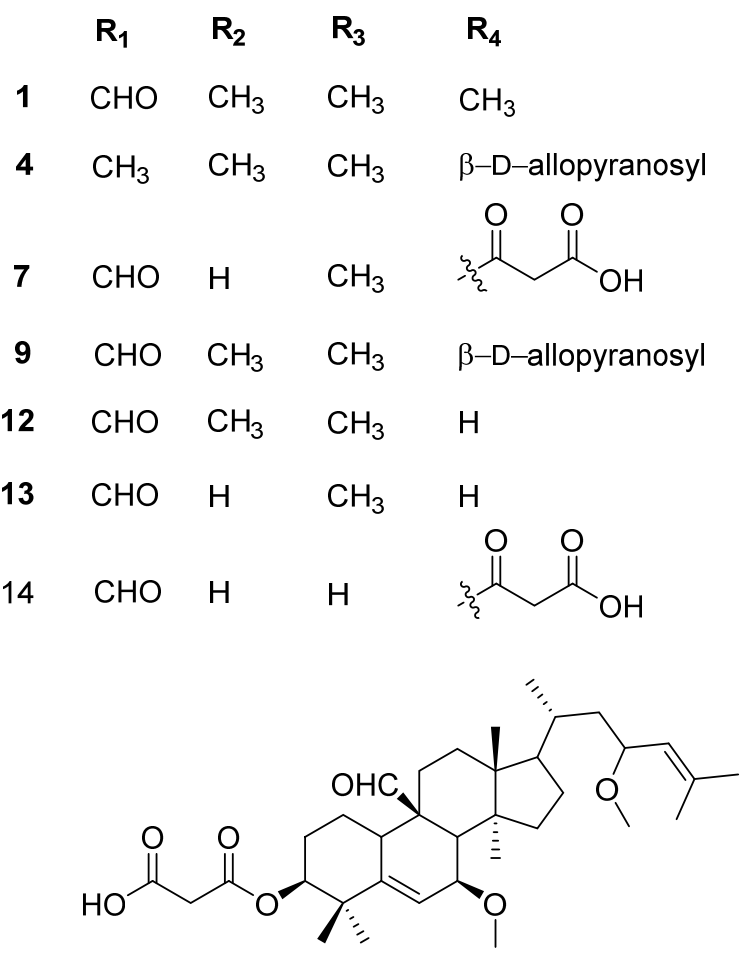

10

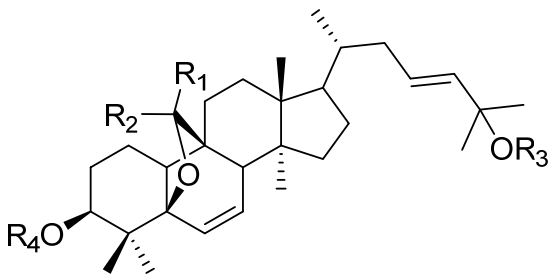
$\begin{array}{llll}\mathbf{R}_{\mathbf{1}} & \mathbf{R}_{\mathbf{2}} & \mathbf{R}_{\mathbf{3}} & \mathbf{R}_{\mathbf{4}}\end{array}$
$2 \quad \mathrm{OCH}_{3} \quad \mathrm{H} \quad \mathrm{CH}_{3} \quad \beta$-D-allopyranosyl
$\begin{array}{lllll}3 & \mathrm{H} & \mathrm{H} & \mathrm{CH}_{3} & \beta \text {-D-allopyranosyl }\end{array}$
$5 \mathrm{OCH}_{3} \quad \mathrm{H} \quad \mathrm{H} \quad \beta$-D-allopyranosyl
$6 \quad \mathrm{H} \quad \mathrm{H} \quad \mathrm{H} \quad \beta$-D-allopyranosyl
$8 \quad-\mathrm{O}-$
$\mathrm{CH}_{3}$ 经竞 $\mathrm{OH}$
$\begin{array}{lllll}11 & \mathrm{OCH}_{3} & \mathrm{H} & \mathrm{H} & \mathrm{H}\end{array}$
$15 \quad \mathrm{H} \quad \mathrm{OCH}_{3} \quad \mathrm{CH}_{3} \quad \beta-\mathrm{D}$-allopyranosyl

Figure 1. The isolated compounds from M. charantia (1-15) and SB203580.

\subsection{Inhibition of IL-6 Expression}

IL-6 is a pleiotropic, pro-inflammatory cytokine produced by various cell types, including lymphocytes, monocytes, and fibroblasts. In joints, the major source of IL-6 is from synovial fibroblasts, with some released by activated macrophages and lymphocytes [23]. Excess IL-6 production contributes to the anemia of chronic disease, which is common in active rheumatoid arthritis, by increasing hepcidin production and inducing thrombocytosis via increased megakaryocyte differentiation [24]. Furthermore, IL-6 may prompt synovial fibroblast differentiation and osteoclast activation, contributing to pannus formation and cartilage and bone destruction [25]. Dysregulation of IL-6 may explain some of the common 
clinical manifestations associated with active rheumatoid arthritis, including fever, weight loss, fatigue, and poor appetite [23].

To examine the inhibitory effects of $M$. charantia on IL-6 expression, LPS-stimulated BMDCs were treated with isolated metabolites 1-15. As Table 1 shows, all of the isolated cucurbitane-type triterpenoids inhibited IL-6 production with IC $\mathrm{C}_{50}$ values of $0.028-1.962$ $\mu \mathrm{M}$, while the positive control SB203580 had an $\mathrm{IC}_{50}$ of $5.000 \mu \mathrm{M}$. Compounds 3, 4, 6, 11, and 12 had dramatic effects, with $\mathrm{IC}_{50}$ values of $0.245,0.363,0.381,0.157$, and $0.028 \mu \mathrm{M}$, respectively.

Table 1. Inhibition of isolated cucurbitane-type triterpenoids (1-15) on IL-6, IL-12 p40, and TNF- $\alpha$ production in LPS-stimulated bone marrow-derived dendritic cells.

\begin{tabular}{|c|c|c|c|}
\hline \multirow{2}{*}{ Compounds } & \multicolumn{3}{|c|}{$\mathrm{IC}_{50}(\mu \mathrm{M})$} \\
\hline & IL-6 & IL-12 p40 & TNF- $\alpha$ \\
\hline 1 & $0.886 \pm 0.118$ & $1.192 \pm 0.104$ & $2.809 \pm 0.264$ \\
\hline 2 & $1.616 \pm 0.211$ & $0.733 \pm 0.041$ & $2.616 \pm 0.181$ \\
\hline 3 & $0.245 \pm 0.008$ & $0.495 \pm 0.003$ & $4.357 \pm 0.037$ \\
\hline 4 & $0.363 \pm 0.015$ & $0.031 \pm 0.001$ & $0.810 \pm 0.068$ \\
\hline 5 & $0.582 \pm 0.024$ & $0.063 \pm 0.017$ & $2.144 \pm 0.151$ \\
\hline 6 & $0.381 \pm 0.039$ & $0.012 \pm 0.000$ & $0.043 \pm 0.006$ \\
\hline 7 & $1.299 \pm 0.222$ & $0.551 \pm 0.048$ & $3.888 \pm 0.149$ \\
\hline 8 & $1.348 \pm 0.052$ & $0.085 \pm 0.005$ & $1.568 \pm 0.209$ \\
\hline 9 & $0.568 \pm 0.004$ & $0.052 \pm 0.005$ & $0.087 \pm 0.033$ \\
\hline 10 & $0.858 \pm 0.002$ & $0.553 \pm 0.010$ & $2.143 \pm 0.003$ \\
\hline 11 & $0.157 \pm 0.011$ & $0.073 \pm 0.086$ & $0.033 \pm 0.002$ \\
\hline 12 & $0.028 \pm 0.005$ & $0.045 \pm 0.026$ & $0.142 \pm 0.009$ \\
\hline 13 & $1.962 \pm 0.096$ & $0.795 \pm 0.086$ & $0.388 \pm 0.015$ \\
\hline 14 & $0.751 \pm 0.038$ & $0.299 \pm 0.002$ & $0.811 \pm 0.005$ \\
\hline 15 & $1.553 \pm 0.245$ & $1.360 \pm 0.101$ & $3.716 \pm 0.011$ \\
\hline SB203580 a & $5.000 \pm 0.080$ & $3.500 \pm 0.080$ & $7.200 \pm 0.060$ \\
\hline
\end{tabular}

a: Positive control

We demonstrated the docking of the active metabolites and SB203580 into 2L3Y protein (Figure 2) using the PyRx 0.9.4 virtual screening software. Table 2 shows the docking score energy and root-mean-square deviation (RMSD) between the active compounds and protein with various interactions, including hydrogen bond interactions and the interaction distances between amino acids and the active sites. From the docking results, compounds 3 , $4,6,11$, and 12 had binding energies of $-7.18,-7.48,-7.26,-6.99$, and $-6.41 \mathrm{kcal} \cdot \mathrm{mol}^{-1}$, respectively. The corresponding ligand interactions of 3 and 4 with 2L3Y protein were hydrogen bond interactions between the enzyme residues and the hydroxyl groups in the sugar rings of the two compounds (Figure 3). As illustrated in Figure 3C, the ligand interactions of 6 with the IL-6 protein involved four hydrogen bonds with Lys156, Thr166, Arg165, and Asn109 with bond distances of 2.3, 2.0, 2.6, and $2.3 \AA$, respectively. These interactions corresponded to the hydrogen-bonding interactions between the enzyme residues and hydroxyl groups in both sugar rings and position C-25. Interestingly, the activities of compounds $\mathbf{1 1}$ and $\mathbf{1 2}$ were interpreted as hydrogen bonds with residues Lys137 and Asn133, respectively, with bond distances of $2.3 \AA$ (Table 2). The corresponding ligand interactions of $\mathbf{1 1}$ and $\mathbf{1 2}$ with the protein involved hydrogen bonds between the enzyme residues and hydroxyl groups at C-25 and C-3, respectively (Figure 3). These findings suggest the important roles of the hydroxyl groups at positions C-3 and C-25 as well as the sugar rings in inhibition of IL-6 expression. 


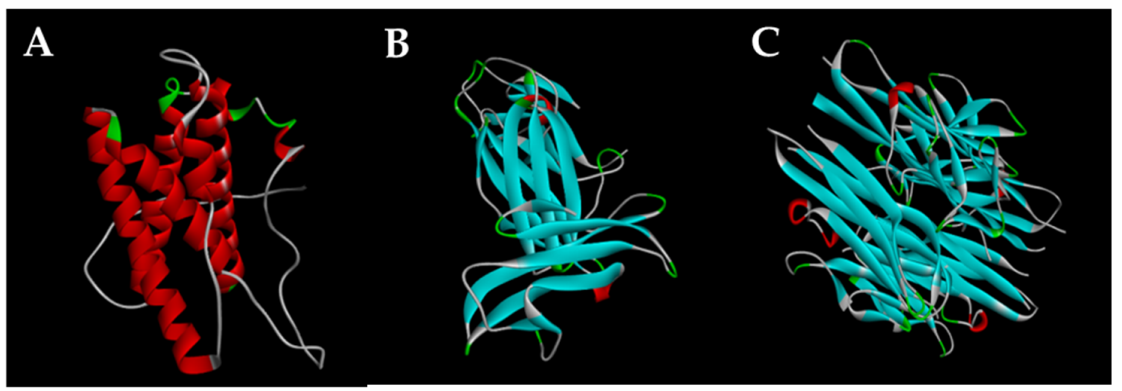

Figure 2. IL-6, IL-12 p40, and TNF- $\alpha$ proteins. (A) 2L3Y, (B) 1 F42 and (C) $2 A Z 5$.

Table 2. Docking simulation results with docking score energy (DS) and root-mean-square deviation (RMSD) between isolated compounds $(\mathbf{3}, \mathbf{4}, \mathbf{6}, \mathbf{1 1}$, and 12) and the 2L3Y protein.

\begin{tabular}{|c|c|c|c|}
\hline Compounds & DS $\left(\mathrm{kcal} \cdot \mathrm{mol}^{-1}\right)$ & RMSD (@) & Interaction with Amino Acid \\
\hline 3 & -7.18 & 18.64 & $\operatorname{Arg} 165(2.3 \AA)$ \\
\hline 4 & -7.48 & 17.07 & Ser $94(2.5 \AA)$, Glu $98(2.2 \AA)$ \\
\hline 6 & -7.26 & 21.27 & $\begin{array}{c}\text { Lys } 156(2.3 \AA), \operatorname{Thr} 166(2.0 \AA), \operatorname{Arg} \\
165(2.6 \AA), \text { Asn } 109(2.3 \AA)\end{array}$ \\
\hline 11 & -6.99 & 18.85 & Lys $137(2.3 \AA)$ \\
\hline 12 & -6.41 & 11.79 & Asn $133(2.3 \AA)$ \\
\hline SB203580 ${ }^{a}$ & -7.96 & 7.02 & $\begin{array}{c}\text { Asn } 133(2.4 \AA) \text {, Ser } 93(1.9 \AA) \text {, Thr } \\
187(2.4 \AA)\end{array}$ \\
\hline
\end{tabular}

a: Positive control.
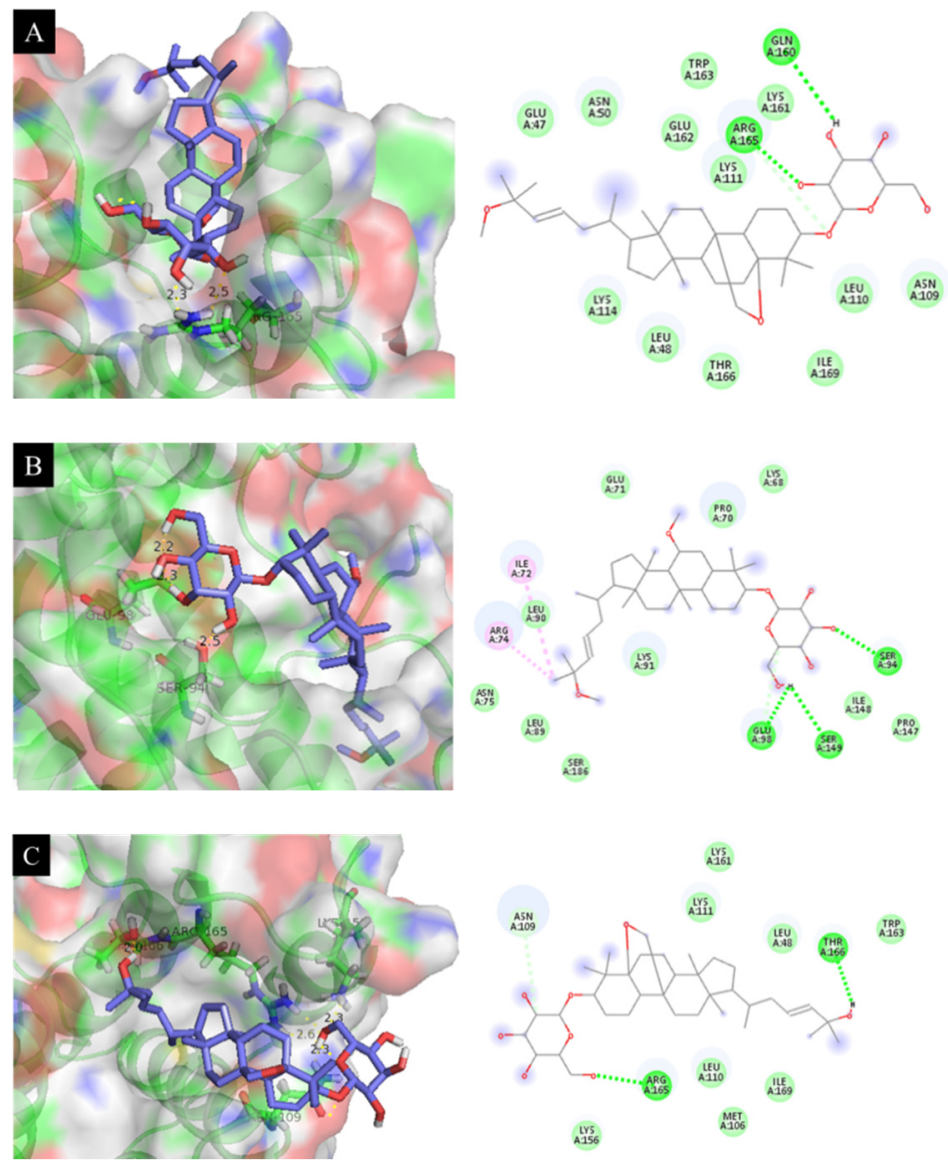

Figure 3. Cont. 

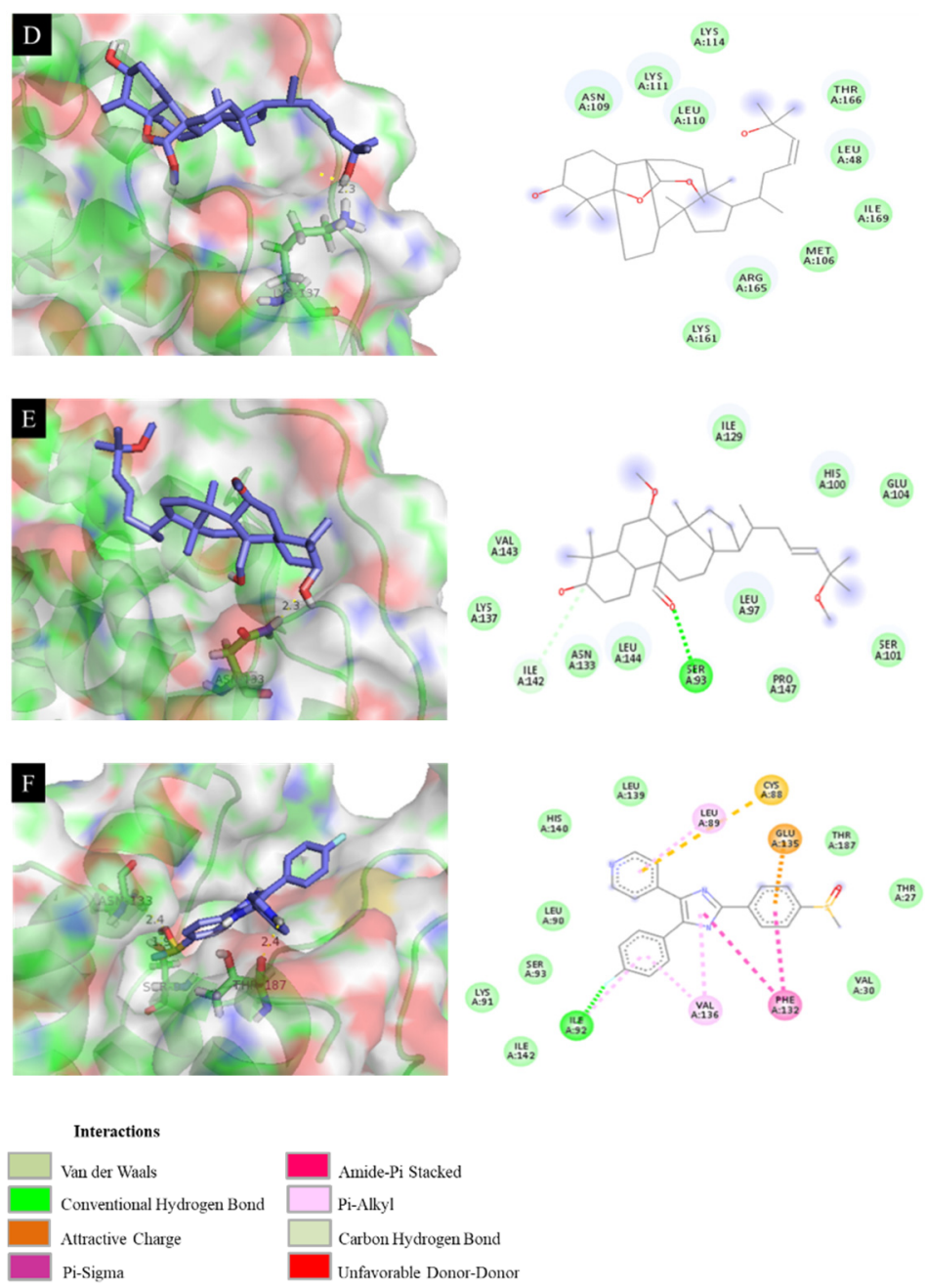

Figure 3. Docking simulation of the interactions between compounds 3 (A), 4 (B), 6 (C), 11 (D), 12 (E), and SB203580 (F), respectively, and the 2L3Y protein of IL-6 expression.

\subsection{Inhibition of IL-12 Expression}

IL-12 is a heterodimeric pro-inflammatory cytokine that was first recovered from EBV-transformed B cell lines [26]. It comprises a 35-kDa light chain (p35) and a 40-kDa heavy chain (p40). p35 is homologous with other single-chain cytokines, whereas p40 is homologous with the extracellular domain of members of the hematopoietic cytokine receptor family. The unusual structure of IL-12 might have evolved from a primordial cytokine in the IL-6 family and one of its receptors [27]. Recent evidence points to a critical role for IL-12 in the pathogenesis of rodent models of Th1-mediated autoimmune diseases, such as type-1 diabetes, rheumatoid arthritis, multiple sclerosis, and inflammatory bowel disease [28].

This study evaluated the inhibitory effects 15 isolated cucurbitane-type triterpenoids (1-15) on IL-12 p40 expression. Surprisingly, all 15 isolated compounds markedly inhibited IL-12 production with IC 50 values of $0.012-1.360 \mu \mathrm{M}$, whereas the positive control SB203580 had an $\mathrm{IC}_{50}$ of $3.500 \mu \mathrm{M}$ (Table 1). Compounds 4-6, 8, 9, 11, and 12 had the greatest activity with $\mathrm{IC}_{50}$ values of $0.031,0.063,0.012,0.085,0.052,0.073$, and $0.045 \mu \mathrm{M}$, respectively. Subsequently, the most active compounds and positive control were docked with the 1F42 protein (Figure 2) of IL-12 p40 in the same grid. The docking results support the inhibition of IL-12 p40 expression by the most active compounds $(\mathbf{4 - 6}, \mathbf{8}, \mathbf{9}, \mathbf{1 1}$, and 12), with binding energies of $-6.93,-7.28,-7.34,-6.98,-7.02,-6.66$, and $-6.32 \mathrm{kcal} \cdot \mathrm{mol}^{-1}$, respectively (Table 3). 
Table 3. Docking simulation results with docking score energy (DS) and root-mean-square deviation (RMSD) between isolated compounds $(\mathbf{4 - 6 , 8 , 9 , 1 1}$, and $\mathbf{1 2})$ and the $1 \mathrm{~F} 42$ protein.

\begin{tabular}{|c|c|c|c|}
\hline Compounds & DS (kcal· mol $\left.{ }^{-1}\right)$ & RMSD ( $\AA$ ) & Interaction with Amino Acid \\
\hline 4 & -6.93 & 12.15 & Leu 107 (2.1 ̊), Phe 106 (2.5 ̊) \\
\hline 5 & -7.28 & 5.67 & Ser 204 (2.3 Å), Leu 107 (2.1 $)$ \\
\hline 6 & -7.34 & 13.21 & Arg $108(2.5 \AA)$, Cys $109(2.4 \AA)$ \\
\hline 8 & -6.98 & 11.93 & Ser $203(2.1 \AA)$, Phe $106(2.3 \AA)$ \\
\hline 9 & -7.02 & 13.86 & $\begin{array}{c}\operatorname{Trp} 297(2.3 \AA), \text { Leu } 107(2.2 \AA) \text {, Phe } 106(2.6 \AA), \\
\text { Lys } 104(2.4 \AA)\end{array}$ \\
\hline 11 & -6.66 & 16.38 & Thr $202(2.4 \AA)$ \\
\hline 12 & -6.32 & 10.39 & Cys 109 (2.2 Å) \\
\hline SB203580 a & -7.41 & 11.14 & Tyr $246(2.3 \AA)$, Pro $178(2.7 \AA)$, Glu $181(2.8 \AA)$ \\
\hline
\end{tabular}

a: Positive control.

All of the corresponding ligand interactions of terpenoids 4-6 and 9 with the 1F42 protein involved hydrogen bonds between the enzyme residues and hydroxyl groups in the sugar rings of these compounds (Figure 4). The great effect of compound 4 was due to two hydrogen bonds with residues Leu107 and Phe106 with bonding distances of 2.1 and $2.5 \AA$, respectively. Compound 5 formed two hydrogen bonds with residues Ser204 and Leu107 with respective bonding distances of 2.3 and $2.1 \AA$. The activity of compound 6 was interpreted as due to two hydrogen bonds with residues Arg108 and Cys109 with bond distances of 2.5 and $2.4 \AA$, respectively (Table 3). The activity of compound 9 resulted from the hydrogen bonds between enzyme residues Leu107, Phe106, and Lys104 and hydroxyl groups in the sugar rings, and between Trp297 and oxygen in the methoxy groups at C-25 (Figure 4E). Compound 8 formed two hydrogen bonds with residues Ser203 and Phe106 with two oxygen atoms of carboxylic acid in malonyl groups (Figure 4D). The activity of compound 11 resulted from hydrogen bonding between the hydroxyl group at C-25 and residue Thr202 with a small bond distance of $2.4 \AA$ (Figure 4F). Compound 12 had a single hydrogen bond between residue Cys109 and the hydroxyl group at C-3 (Figure 4G). These data indicate the vital role of cucurbitane-type triterpenoids in the inhibition of IL-12 p40 production.

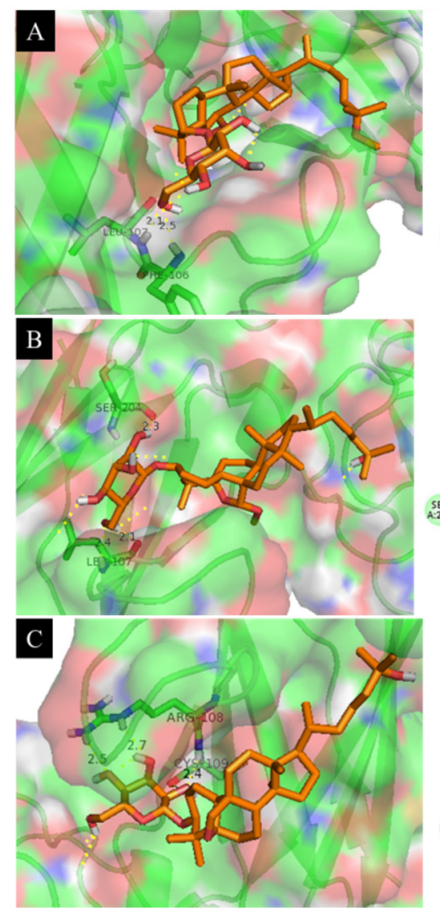

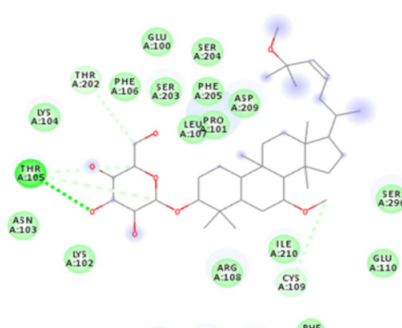
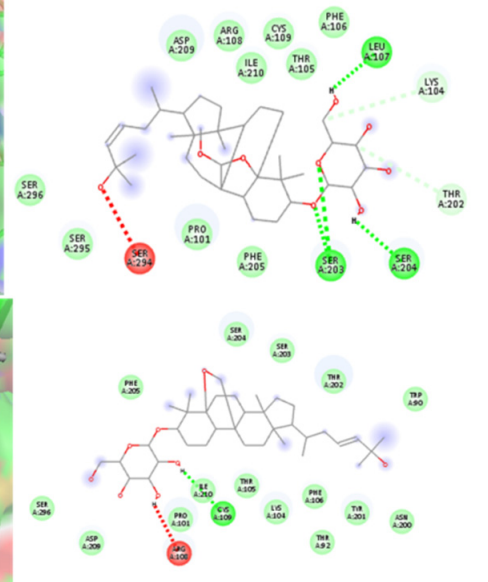
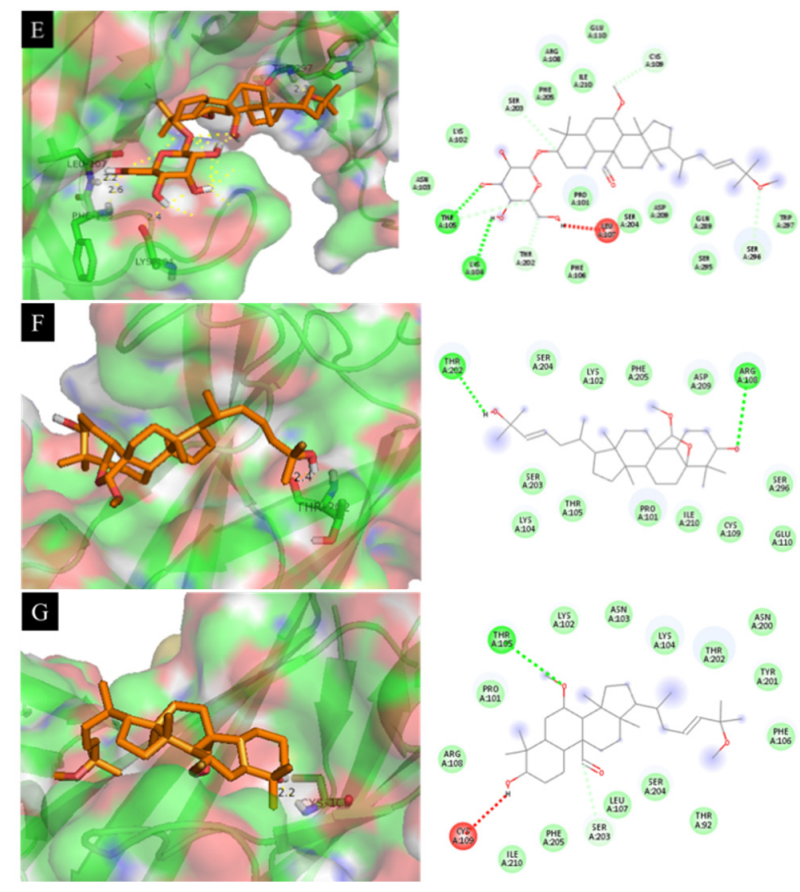

Figure 4. Cont. 

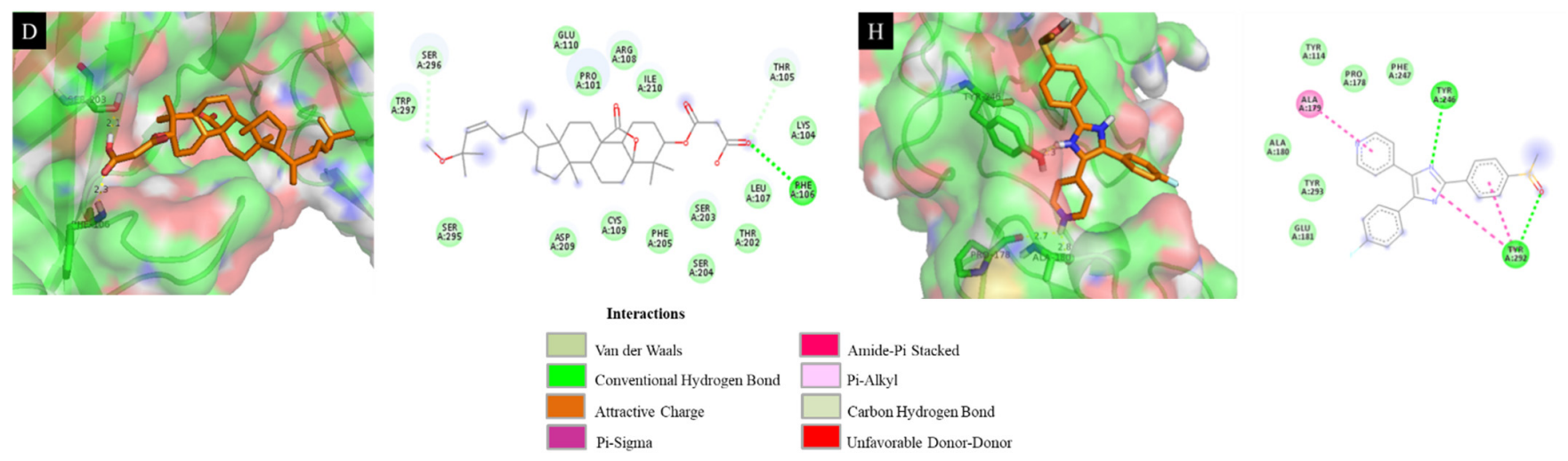

Figure 4. Docking simulation of the interactions between compounds 4-6 (A-C), 8 (D), 9 (E), 11 (F), 12 (G), and SB203580 (H), respectively, and the 1F42 protein of IL-12 p40 expression.

\subsection{Inhibition of TNF- $\alpha$ Production}

TNF- $\alpha$ is produced by macrophages during inflammation and can be activated by the endotoxin LPS. It is a multifunctional Th1 cytokine and one of the most important inflammatory cytokines. TNF- $\alpha$ plays a role in the pathogenesis of inflammatory diseases such as Crohn's disease, rheumatoid arthritis, diabetes mellitus, and systemic lupus erythematosus $[29,30]$.

As with their effects on IL-6 and IL-12 p40 expression, all of the isolated cucurbitanetype triterpenoids (1-15) inhibited TNF- $\alpha$ production with $\mathrm{IC}_{50}$ values of $0.033-4.357 \mu \mathrm{M}$, which are lower than the $\mathrm{IC}_{50}$ of $7.200 \mu \mathrm{M}$ of the positive control SB203580 (Table 1). Compounds 4, 6, 9, and 11-14 had the greatest effect, with $\mathrm{IC}_{50}$ values of $0.810,0.043,0.087$, $0.033,0.142,0.388$, and $0.811 \mu \mathrm{M}$, respectively. These compounds were docked with $2 \mathrm{AZ} 5$ protein in the same grid (Figure 2). The docking results showed the remarkable effects of the most active compounds $(\mathbf{4}, \mathbf{6}, \mathbf{9}$, and 11-14) with binding energies of $-8.23,-8.40$, $-8.22,-8.72,-7.83,-8.39$, and $-8.10 \mathrm{kcal} \cdot \mathrm{mol}^{-1}$, respectively (Table 4 ).

Table 4. Docking simulation results with docking score energy (DS) and root-mean-square deviation (RMSD) between isolated compounds $(\mathbf{4}, \mathbf{6 , 9}$, and $\mathbf{1 1}-\mathbf{1 4})$ and the $2 \mathrm{AZ5}$ protein.

\begin{tabular}{|c|c|c|c|}
\hline Compounds & 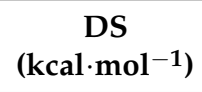 & RMSD (Å) & Interaction with Amino Acid \\
\hline 4 & -8.23 & 10.86 & Tyr 59 (2.1 ̊), Gln 125 (2.5 ̊), Gly 121 (2.2 ̊) \\
\hline 6 & -8.40 & 12.39 & Leu $55(2.4 \AA), G \ln 125(2.7 \AA)$ \\
\hline 9 & -8.22 & 9.15 & Gly $121(2.4 \AA)$ \\
\hline 11 & -8.72 & 15.28 & Ser $95(2.6 \AA), G \ln 125(2.1 \AA)$ \\
\hline 12 & -7.83 & 14.34 & Tyr $151(2.3 \AA)$, Leu $120(2.6 \AA)$, Tyr 59 (2.2 $)$ \\
\hline 13 & -8.39 & 9.48 & Gly $121(2.3 \AA)$, Leu $120(1.9 \AA)$, Ser $60(2.5 \AA)$ \\
\hline 14 & -8.10 & 13.16 & Tyr $119(2.3 \AA)$ \\
\hline SB203580 ${ }^{a}$ & -8.22 & 14.53 & Leu $55(2.8 \AA)$, Tyr $151(2.0 \AA)$ \\
\hline
\end{tabular}

The interactions of $\mathbf{4}, \mathbf{6}$, and $\mathbf{9}$ with the TNF- $\alpha$ protein involved hydrogen bonds between enzyme residues and the hydroxyl groups in both sugar rings (Figure 5). As illustrated in Figure 5A, compound 4 formed three hydrogen bonds with the residues Tyr59, Gln125, and Gly121 with bond distances of 2.1, 2.5, and $2.2 \AA$, respectively. Compound 6 formed two hydrogen bonds with Leu 55 and Gln125 of the 2AZ5 protein with bond distances of 2.4 and $2.7 \AA$, respectively (Figure $5 \mathrm{~B}$ ). Compound 9 formed a hydrogen bond with Gly121 with a bonding distance of $2.4 \AA$ (Figure 5C). Compound $\mathbf{1 1}$ formed two hydrogen bonds between the hydroxyl group at C-25 and residues Ser95 and Gln125 with bond distances of 2.6 and $2.1 \AA$, respectively (Figure 5D). Compound 12 formed three hydrogen bonds between a hydroxyl group at C-25, oxygen in the methoxy group at C-25, and oxygen in the aldehyde group at C-19 and the residues Tyr151, Tyr59, and Leu120 with 
bond distances of 2.3, 2.2, and $2.6 \AA$, respectively (Figure 5E). The activity of compound $\mathbf{1 3}$ was based on bonding between a hydroxyl group at C-3 and oxygen in the methoxy group at C-25 and residues Gly121, Leu120, and Ser60 with bonding distances of 2.3, 1.9, and $2.5 \AA$, respectively (Figure 5F). Compound $\mathbf{1 4}$ formed a single bond between the hydroxyl group at C-25 and residue Tyr119 with a bond distance of $2.3 \AA$ (Figure 5G). This demonstrates the roles of the hydroxyl groups at both C-3 and C-25, and the sugar rings, methoxy group at $\mathrm{C}-25$, and the aldehyde group at $\mathrm{C}-19$ in the inhibition of TNF- $\alpha$ expression.
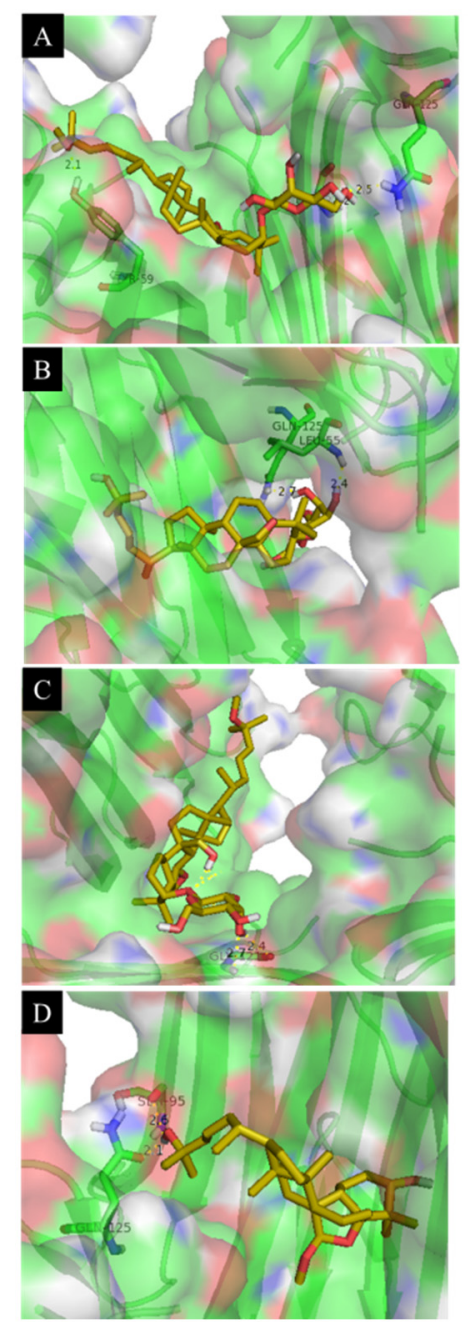
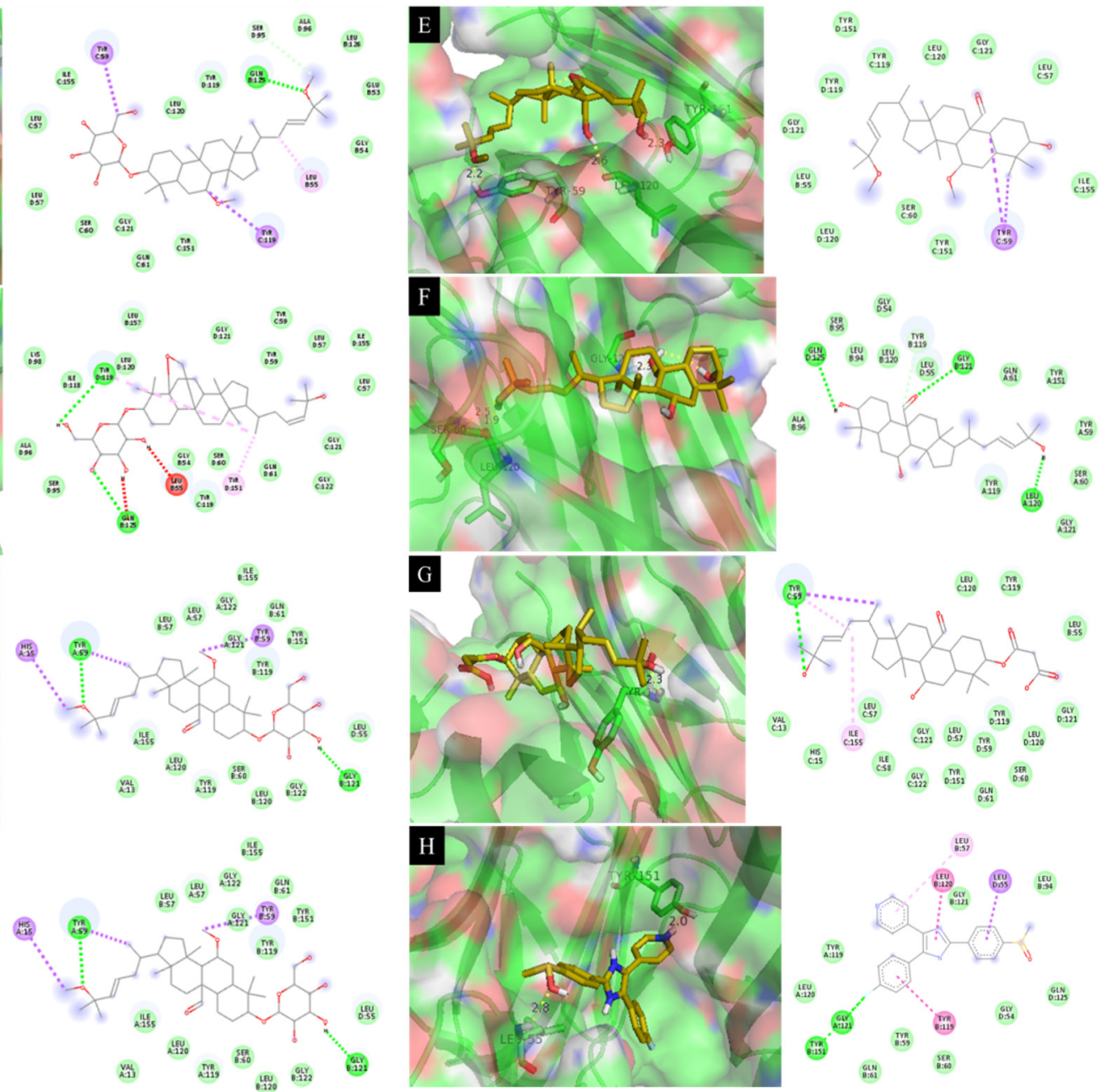

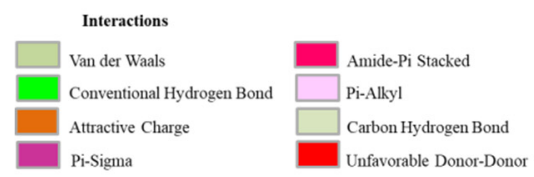

Figure 5. Docking simulation of the interactions between compounds 4 (A), 6 (B), 9 (C), 11-14 (D-G), and SB203580 (H), respectively, and the $2 \mathrm{AZ} 5$ protein of TNF- $\alpha$ expression $(\mathbf{A}-\mathbf{H})$.

In conclusion, 15 cucurbitane-type triterpenoids (1-15) were isolated from $M$. charantia fruit. Their structures were unambiguously established and their inhibitory effects on pro-inflammatory cytokine (IL-6, IL-12 p40, and TNF- $\alpha$ ) production were characterized. The potential anti-inflammatory effects of the isolated triterpenoids (1-15) increase our understanding of the chemotaxonomic properties of the Cucurbitaceae, and the mechanisms underlying the anti-inflammatory properties of $M$. charantia. This is the first report of the inhibitory effects of isolated constituents of $M$. charantia fruit on the pro-inflammatory cytokines IL-6, IL-12 p40, and TNF- $\alpha$. Based on this study and in silico simulations, we 
determined that the ligand likely docked in the receptor. Thus, compounds isolated from $M$. charantia fruit are potential candidates for treating inflammation and related diseases.

\section{Materials and Methods}

\subsection{General Experimental Procedures}

The optical rotation values were confirmed using a JASCO DIP-370 digital polarimeter (Hachioji, Tokyo, Japan). ESI mass spectra were obtained using an Agilent 1200 LCMSD Trap spectrometer (Kyoto, Japan). LC-MS/MS analysis was performed by using a Shimadzu LCMS-8040 system (Kyoto, Japan) in positive and negative mode. NMR spectra were carried out on a JEOL ECA 400 and 600 spectrometer (JEOL Ltd., Tokyo, Japan) with TMS used as an internal standard. NMR data processing was recorded with the MestReNova 14.0 program. Sephadex LH-20 (Sigma-Aldrich, St. Louis, MO, USA), and Diaion HP-20 (Supelco ${ }^{\mathrm{TM}}$, Bellefonte, PA, USA) resins. Thin-layer chromatography (TLC) and YMC RP-18 resins were performed using pre-coated silica gel $60 \mathrm{~F}_{254}$ and RP- $18 \mathrm{~F}_{254 \mathrm{~S}}$ plates (both $0.25 \mathrm{~mm}$, Merck, Darmstadt, Germany), and the spots were detected under UV light at 254 , and $365 \mathrm{~nm}$ wavelengths and using $10 \% \mathrm{H}_{2} \mathrm{SO}_{4}$, followed by heating for 3-5 $\mathrm{min}$. The chemicals used were purchased from commercial suppliers and used as received. All chemical reagents were purchased from Sigma-Aldrich (St. Louis, MO, USA).

\subsection{Plant Material}

The fruits of Momordica charantia were obtained from an herbal company. Plant identification was verified by an expert botanist (Prof. Young Ho Kim). A representative specimen of the M. charantia (CNU MC1917) was conserved in the Herbarium of the Natural Product Laboratory, Chungnam National University, Daejeon, Korea.

\subsection{Extraction and Isolation}

The dried fruits of $M$. charantia $(5.0 \mathrm{~kg}$ ) were cut into pieces and extracted with $\mathrm{MeOH}$ $(10 \mathrm{~L} \times 3$ times) at room temperature. The methanol solution was concentrated using a rotatory evaporator to give a residue of the $\mathrm{MeOH}$ extract $(360 \mathrm{~g})$, which was further suspended in $\mathrm{H}_{2} \mathrm{O}$ and successively partitioned with $n$-hexane $(\mathrm{H})$, dichloromethane $\left(\mathrm{CH}_{2} \mathrm{Cl}_{2}\right)$, and ethyl acetate (EtOAc) to afford $\mathrm{H}(300 \mathrm{~g}), \mathrm{D}(35 \mathrm{~g})$ EtOAc $(\mathrm{E}, 40 \mathrm{~g})$, and aqueous extracts $(\mathrm{W})$, respectively. Extract $\mathrm{D}$ was separated on silica gel using a mobile phase of $\mathrm{CH}_{2} \mathrm{Cl}_{2}-\mathrm{MeOH}$ (100:1-1:1, v/v) to afford eight fractions D1-D8, respectively. Fraction D3 was further separated into nine subfractions by YMC CC, eluted with a gradient of $\mathrm{MeOH}-\mathrm{H}_{2} \mathrm{O}$ (1:3 to 1:0, $v / v$ ) to give four subfractions (D3A-D3D), respectively. Fraction D3C was further purified by $\mathrm{YMC} C \mathrm{CC}$ with $\mathrm{MeOH}^{-} \mathrm{H}_{2} \mathrm{O}(2: 1-4: 1, v / v)$ to obtain compounds 1 (6.6 mg), 2 (5.8 mg), 3 (9.5 mg), $4(15.6 \mathrm{mg})$, and 5 (16.8 mg). Purification of the subfraction D3D via silica gel column eluted with EtOAc-MeOH-H $\mathrm{H}_{2} \mathrm{O}(7: 1: 0.1, v / v / v)$ was further isolated by $\mathrm{RP}_{-} \mathrm{C}_{18}$ silica gel $\left(\mathrm{MeOH}-\mathrm{H}_{2} \mathrm{O}, 3: 1,6: 1, v / v\right)$ to yield compounds $\mathbf{7}(9.0 \mathrm{mg}), \mathbf{8}(4.9 \mathrm{mg}), \mathbf{1 1}(26.5 \mathrm{mg})$, and $\mathbf{1 5}(6.6 \mathrm{mg})$. Fraction D6 was isolated by RP$\mathrm{C}_{18}$ silica gel eluted with $\left(\mathrm{MeOH}-\mathrm{H}_{2} \mathrm{O}, 3: 1,6: 1, v / v\right)$, and Sephadex ${ }^{\mathrm{TM}} \mathrm{LH}-20$ column using $\mathrm{MeOH}-\mathrm{H}_{2} \mathrm{O}(5: 1 . v / v)$ to afford compounds $\mathbf{9}(7.2 \mathrm{mg}), \mathbf{1 0}(15.3 \mathrm{mg}), \mathbf{1 2}(27.8 \mathrm{mg})$, 13 (315.9 mg), $14(3.0 \mathrm{mg})$, and $\mathbf{6}(24.0 \mathrm{mg})$.

Physical and the Key of Spectroscopic Data of New Natural Compound

Compound 1. White amorphous powder, $[\alpha]_{\mathrm{D}}{ }^{20}-77.8(c=0.2, \mathrm{MeOH}) ; \mathrm{IR}:{ }^{1} \mathrm{H}-\mathrm{NMR}$ $\left(400 \mathrm{MHz}, \mathrm{CDCl}_{3}\right) \delta_{\mathrm{H}} 1.07(\mathrm{~s}, 3 \mathrm{H}, \mathrm{H}-26), 1.15(\mathrm{~s}, 3 \mathrm{H}, \mathrm{H}-26), 1.25(\mathrm{~s}, 3 \mathrm{H}, \mathrm{H}-26), 1.43(\mathrm{~s}, 3 \mathrm{H}$, $\mathrm{H}-26), 1.07$ (s, 3H, H-26), 1.07 (s, 3H, H-26), 1.07 (s, 3H, H-26), 1.07 (s, 3H, H-26), 1.50 (s, $6 \mathrm{H}, \mathrm{H}-26$, and $\mathrm{H}-28), 5.71,5.68(\mathrm{OMe}-3)$ and ${ }^{13} \mathrm{C}-\mathrm{NMR}\left(100 \mathrm{MHz}, \mathrm{CDCl}_{3}\right): \delta_{\mathrm{C}} 21.7(\mathrm{C}-1)$, 29.9 (C-2), 80.0 (C-3), 41.7 (C-4), 146.1 (C-5), 121.5 (C-6), 75.1 (C-7), 50.6 (C-8), 36.9 (C-9), 22.7 (C-10), 29.4 (C-11), 29.4 (C-12), 45.7 (C-13), 48.2 (C-14), 34.9 (C-15), 27.7 (C-16), 50.1 (C-17), 15.0 (C-18), 208.0 (C-19), 36.5 (C-20), 18.9 (C-21), 39.5 (C-22), 128.5 (C-23), 137.1 (C-24), 75.6 (C-25), 30.8 (C-26), 30.8 (C-27), 26.2 (C-28), 27.3 (C-29), 18.2 (C-30), 56.1 (3-OMe), 51.2 (7-OMe), 50.3 (25-OMe). HR-ESI-MS: $m / z:[\mathrm{M}+\mathrm{Na}]^{+} m / z$ 537.3918. 


\subsection{Cell Culture and Reagents}

BMDCs were grown from wild-type C57BL/ 6 mice (Orient Bio Inc., Seoul, Korea) $[31,32]$. All animal procedures were approved by and performed according to the guidelines of the Institutional Animal Care and Use Committee of Jeju National University (\#2016-0059). Briefly, bone marrow from the tibia and femur was obtained by flushing with Dulbecco's Modified Eagle Medium (DMEM; Welgene, Gyeongsan, Korea) and bone marrow cells were cultured in RPMI-1640 medium containing 10\% heat-inactivated fetal bovine serum (FBS; Gibco, New York, USA), $50 \mu \mathrm{M}$ of 2-ME, and $2 \mathrm{mM}$ of glutamine, supplemented with $3 \%$ J558L hybridoma cell culture supernatant containing the granulocyte-macrophage colonystimulating factor (GM-CSF). The culture medium containing GM-CSF was replaced every other day. On day 6 of culturing, non-adherent cells and loosely adherent DC aggregates were harvested, washed, and resuspended in RPMI-1640, supplemented with 5\% FBS. DCs were incubated in 48 -well plates at a density of $1 \times 10^{5}$ cells $/ 0.5 \mathrm{~mL}$ and then treated with the isolated compounds at the indicated concentration for $1 \mathrm{~h}$ before stimulation with $10 \mathrm{ng} / \mathrm{mL}$ of LPS from Salmonella minnesota (Alexis, New York, NY, USA). Supernatants were harvested $18 \mathrm{~h}$ after stimulation. Concentrations of murine IL-12 p40, IL-6, and TNF- $\alpha$ in the culture supernatants were determined by ELISA (BD PharMingen, San Diego, CA, USA) following the manufacturer's protocol [31,32]. All experiments were carried out at least three times. Data are presented as the mean and the standard deviation (SD) of three independent experiments.

\subsection{Cytokine Production Measurements}

The BMDCs were incubated in 48-well plates in $0.5 \mathrm{~mL}$ containing $1 \times 10^{5}$ cells per well, and then treated with isolated compounds 1-15 at the indicated concentration for $1 \mathrm{~h}$ before stimulation with $10 \mathrm{ng} / \mathrm{mL}$ LPS from Salmonella Minnesota (Alexis, New York, NY, USA). Supernatants were collected $18 \mathrm{~h}$ after stimulation. Concentrations of murine IL-12 p40, IL-6, and TNF- $\alpha$ in the culture supernatants were identified by ELISA (BD PharMingen, San Diego, CA, USA) according to the manufacturer's instructions.

The inhibitory activity (I) was expressed as the inhibition rate (\%), which was calculated from the following formula:

$$
\mathrm{I}=\frac{\mathrm{Cdvc}-\mathrm{Cdcc}}{\mathrm{Cdvc}} \times 100
$$

Cdvc: Cytokine level (ng/mL) in vehicle-treated DCs; Cdcc: Cytokine level (ng/mL) in compound treated DC. The data was obtained by at least three independent experiments performed in triplicate.

\subsection{Cell Viability Assay}

To identify the effects of isolated compounds on cell viability, the MTT assay was carried out [33]. BMDCs were incubated with 1 to $50 \mu \mathrm{M}$ of isolated compounds for $18 \mathrm{~h}$. The results demonstrate that tested compounds (1-15) displayed no notable cytotoxicity against BMDCs.

\subsection{Statistical Analysis}

All results are presented as the means $\pm \mathrm{SD}$. Data were analyzed by one-factor analysis of variance (ANOVA). ${ }^{*} p$-value $<0.05$, and ${ }^{* *} p$-value $<0.01$ were considered statistically significant. All experiments were repeated at least three times independently.

\subsection{Preparation of Structures of Proteins Molecular Docking}

The structures of IL-6, IL-12 p40, and TNF- $\alpha$ proteins resolved using X-ray diffraction (resolution of $2.16 \AA$ ) were downloaded from the Worldwide Protein Data Bank (PDB: 2L3Y, 1F42, and 2AZ5). The crystal structure was prepared for docking using Discovery Studio Client (2020). This step mainly involved the addition of missing disulfide bonds, removal of water molecules, the addition of missing hydrogen atoms, filling of missing 
amino acids side chains, and optimization of hydrogen bonds. The PyRx 0.9.4 virtual screening software was then used for restrained minimization until the average RMSD of the non-hydrogen atoms converged to $0.30 \AA$. Thus, this step allowed sufficient movement of heavy atoms to relax strained bonds, angles, and clashes.

The 2D chemical structure (flat structure) of the isolated compounds and positive control were automatically converted to the 3D chemical structure (three-dimensional structure) by the ChemBioOffice 12.0 software. The energy of the generated compounds was then minimized using the PyRx 0.9.4 software.

\subsection{Molecular Docking of Isolated Compounds with IL-6, IL-12 p40, and TNF- $\alpha$ Proteins}

Docking of compounds into prepared protein via conducting the docking process with the PyRx 0.9.4 software was carried out by following the method of placing compound fragments into the triangle matching and retaining the eight best configurations of each compound in the bonding complex for further analysis. The grid for docking studies was generated to enclose all the residues of IL-6, IL-12 p40, and TNF- $\alpha$ proteins making polar interactions with the atoms of the positive control. The best configuration is the one with the lowest docking score (DS) energy $\left(\mathrm{kcal}_{\mathrm{mol}}{ }^{-1}\right)$. This score is the total energy consumed for the formation of bonding interactions between the compounds and the protein selected.

\subsection{Docking Results Analysis}

Discovery Studio Client was used for the analysis of the interactions between the compounds and target protein, and the performance of interaction on 2D and 3D planes. Various interactions, such as hydrogen bonds, van der Waals interactions, $\pi$-anion bonds, $\pi-\pi$ bonds, and the interaction distance between amino acids and the active sites of compounds were plotted. Van der Waals interactions are detected by contact with hydrophilic and hydrophobic surfaces between the compounds and their bonding point.

Author Contributions: Isolation, structure, and identification of metabolites, T.Q.C., N.V.P., D.G. and S.Y.Y.; Bioassay experiments, V.-D.N., L.B.V., H.L.T.A. and Y.S.K. All research and the manuscript were carried out based on the planning of J.H.K. and S.Y.Y. All authors have read and agreed to the published version of the manuscript.

Funding: The research was supported by the Basic Science Research Program through the National Research Foundation of Korea (NRF) funded by the Ministry of Education, Science, and Technology (NRF-2018R1A6A3A11047338), and the basic research project (PJ016127032021) of the National Institute of Horticultural and Herbal Sciences, RDA.

Institutional Review Board Statement: The study was conducted according to the guidelines and approved by the Institutional Animal Care and Use Committee of Jeju National University (\#2016-0059).

Informed Consent Statement: Not applicable.

Data Availability Statement: Not applicable.

Acknowledgments: The research was supported by the Basic Science Research Program through the National Research Foundation of Korea (NRF) funded by the Ministry of Education, Science, and Technology (NRF-2018R1A6A3A11047338), and the basic research project (PJ016127032021) of the National Institute of Horticultural and Herbal Sciences, RDA.

Conflicts of Interest: The authors declare no conflict of interest.

Sample Availability: Sample of the isolated compounds (1-15) available from the authors.

\section{References}

1. Brooks-Worrell, B.; Palmer, J. Immunology in the Clinic Review Series; focus on metabolic diseases: Development of islet autoimmune disease in type 2 diabetes patients: Potential sequelae of chronic inflammation. Clin. Exp. Immunol. 2012, 167, 40-46. [CrossRef]

2. Cao, T.Q.; Tran, M.H.; Kim, J.A.; Tran, P.T.; Lee, J.-H.; Woo, M.H.; Lee, H.-K.; Min, B.S. Inhibitory effects of compounds from Styrax obassia on NO production. Bioorg. Med. Chem. Lett. 2015, 25, 5087-5091. [CrossRef] 
3. Wang, R.X.; Zhou, M.; Ma, H.L.; Qiao, Y.B.; Li, Q.S. The Role of Chronic Inflammation in Various Diseases and Anti-inflammatory Therapies Containing Natural Products. ChemMedChem 2021, 16, 1576-1592. [CrossRef]

4. Subramaniam, S.; Selvaduray, K.R.; Radhakrishnan, A.K. Bioactive compounds: Natural defense against cancer? Biomolecules 2019, 9, 758. [CrossRef] [PubMed]

5. Mushtaq, S.; Abbasi, B.H.; Uzair, B.; Abbasi, R. Natural products as reservoirs of novel therapeutic agents. EXCLI J. 2018, 17, 420.

6. Raman, A.; Lau, C. Anti-diabetic properties and phytochemistry of Momordica charantia L. (Cucurbitaceae). Phytomedicine 1996, 2, 349-362. [CrossRef]

7. Perera, W.H.; Shivanagoudra, S.R.; Pérez, J.L.; Kim, D.M.; Sun, Y.; Jayaprakasha, G.K.; Patil, B.S. Anti-Inflammatory, antidiabetic properties and in silico modeling of cucurbitane-type triterpene glycosides from fruits of an indian cultivar of Momordica charantia L. Molecules 2021, 26, 1038. [CrossRef]

8. Kubola, J.; Siriamornpun, S. Phenolic contents and antioxidant activities of bitter gourd (Momordica charantia L.) leaf, stem and fruit fraction extracts in vitro. Food Chem. 2008, 110, 881-890. [CrossRef] [PubMed]

9. Akihisa, T.; Higo, N.; Tokuda, H.; Ukiya, M.; Akazawa, H.; Tochigi, Y.; Kimura, Y.; Suzuki, T.; Nishino, H. Cucurbitane-type triterpenoids from the fruits of Momordica charantia and their cancer chemopreventive effects. J. Nat. Prod. 2007, 70, 1233-1239. [CrossRef]

10. Alam, S.; Asad, M.; Asdaq, S.M.B.; Prasad, V.S. Antiulcer activity of methanolic extract of Momordica charantia L. in rats. J. Ethnopharmacol. 2009, 123, 464-469. [CrossRef] [PubMed]

11. Wang, N.; Yang, L.; Guo, X.-Y.; Zhang, Y.-Y.; Zhang, Y.; Liu, X.-W. Novel cucurbitane-type triterpene saponins from Hemsleya amabilis. J. Asian Nat. Prod. Res. 2020, 22, 30-37. [CrossRef] [PubMed]

12. Sahranavard, S.; Naghibi, F.; Siems, K.; Jenett-Siems, K. New cucurbitane-type triterpenoids from Bryonia aspera. Planta Med. 2010, 76, 1014-1017. [CrossRef] [PubMed]

13. Chen, C.; Qiang, S.; Lou, L.; Zhao, W. Cucurbitane-type triterpenoids from the stems of Cucumis melo. J. Nat. Prod. 2009, 72, 824-829. [CrossRef] [PubMed]

14. Zhu, N.; Sun, Z.; Hu, M.; Li, Y.; Zhang, D.; Wu, H.; Tian, Y.; Li, P.; Yang, J.; Ma, G. Cucurbitane-type triterpenes from the tubers of Hemsleya penxianensis and their bioactive activity. Phytochemistry 2018, 147, 49-56. [CrossRef]

15. Chen, J.-C.; Zhang, G.-H.; Zhang, Z.-Q.; Qiu, M.-H.; Zheng, Y.-T.; Yang, L.-M.; Yu, K.-B. Octanorcucurbitane and cucurbitane triterpenoids from the tubers of Hemsleya endecaphylla with HIV-1 inhibitory activity. J. Nat. Prod. 2008, 71, 153-155. [CrossRef]

16. Huang, H.-T.; Zhang, L.-J.; Huang, H.-C.; Hwang, S.-Y.; Wu, C.-L.; Lin, Y.-C.; Liaw, C.-C.; Cheng, Y.-Y.; Morris-Natschke, S.L.; Huang, C.-Y. Cucurbitane-Type Triterpenoids from the Vines of Momordica charantia and Their Anti-inflammatory Activities. J. Nat. Prod. 2020, 83, 1400-1408. [CrossRef] [PubMed]

17. Harinantenaina, L.; Tanaka, M.; Takaoka, S.; Oda, M.; Mogami, O.; Uchida, M.; Asakawa, Y. Momordica charantia constituents and antidiabetic screening of the isolated major compounds. Chem. Pharm. Bull. 2006, 54, 1017-1021. [CrossRef]

18. Murakami, T.; Emoto, A.; Matsuda, H.; Yoshikawa, M. Medicinal foodstuffs. XXI. Structures of new cucurbitane-type triterpene glycosides, goyaglycosides-a,-b,-c,-d,-e,-f,-g, and-h, and new oleanane-type triterpene saponins, goyasaponins I, II, and III, from the fresh fruit of Japanese Momordica charantia L. Chem. Pharm. Bull. 2001, 49, 54-63. [CrossRef]

19. Okabe, H.; Miyahara, Y.; Yamauchi, T. Studies on the constituents of Momordica charantia L. III. Characterization of new cucurbitacin glycosides of the immature fruits. Structures of momordicosides G, F1, F2 and I. Chem. Pharm. Bull. 1982, 30, 3977-3986. [CrossRef]

20. Liu, J.-Q.; Chen, J.-C.; Wang, C.-F.; Qiu, M.-H. New cucurbitane triterpenoids and steroidal glycoside from Momordica charantia. Molecules 2009, 14, 4804-4813. [CrossRef] [PubMed]

21. Tuan, N.Q.; Lee, D.-H.; Oh, J.; Kim, C.S.; Heo, K.-S.; Myung, C.-S.; Na, M. Inhibition of proliferation of vascular smooth muscle cells by cucurbitanes from Momordica charantia. J. Nat. Prod. 2017, 80, 2018-2025. [CrossRef] [PubMed]

22. Yue, J.; Sun, Y.; Xu, J.; Cao, J.; Chen, G.; Zhang, H.; Zhang, X.; Zhao, Y. Cucurbitane triterpenoids from the fruit of Momordica charantia L. and their anti-hepatic fibrosis and anti-hepatoma activities. Phytochemistry 2019, 157, 21-27. [CrossRef] [PubMed]

23. Yoshizaki, K.; Nishimoto, N.; Mihara, M.; Kishimoto, T. Therapy of Rheumatoid Arthritis by Blocking IL-6 Signal Transduction with a Humanized Anti-IL-6 Receptor Antibody. Springer Semin. Immunopathol. 1998, 20, 247-259. [CrossRef] [PubMed]

24. Hennigan, S.; Kavanaugh, A. Interleukin-6 inhibitors in the treatment of rheumatoid arthritis. Ther. Clin. Risk Manag. 2008, 4, 767.

25. Kudo, O.; Sabokbar, A.; Pocock, A.; Itonaga, I.; Fujikawa, Y.; Athanasou, N. Interleukin-6 and interleukin-11 support human osteoclast formation by a RANKL-independent mechanism. Bone 2003, 32, 1-7. [CrossRef]

26. Zundler, S.; Neurath, M.F. Interleukin-12: Functional activities and implications for disease. Cytokine Growth Factor. Rev. 2015, 26, 559-568. [CrossRef]

27. Trinchieri, G. Interleukin-12 and the regulation of innate resistance and adaptive immunity. Nat. Rev. Immunol. 2003, 3, 133-146. [CrossRef]

28. Kim, T.S.; Kang, B.; Lee, M.; Choe, Y.K.; Hwang, S. Inhibition of interleukin-12 production by auranofin, an anti-rheumatic gold compound, deviates CD4+ T cells from the Th1 to the Th2 pathway. Br. J. Pharmacol. 2001, 134, 571-578. [CrossRef]

29. Romanowska-Próchnicka, K.; Felis-Giemza, A.; Olesińska, M.; Wojdasiewicz, P.; Paradowska-Gorycka, A.; Szukiewicz, D. The Role of TNF- $\alpha$ and Anti-TNF- $\alpha$ Agents during Preconception, Pregnancy, and Breastfeeding. Int. J. Mol. Sci. 2021, $22,2922$. [CrossRef] 
30. Ting, H.-K.; Chen, C.-L.; Meng, E.; Cherng, J.-H.; Chang, S.-J.; Kao, C.-C.; Yang, M.-H.; Leung, F.-S.; Wu, S.-T. Inflammatory Regulation by TNF- $\alpha$-Activated Adipose-Derived Stem Cells in the Human Bladder Cancer Microenvironment. Int. J. Mol. Sci. 2021, 22, 3987. [CrossRef]

31. Vinh, L.B.; Heo, M.; Phong, N.V.; Ali, I.; Koh, Y.S.; Kim, Y.H.; Yang, S.Y. Bioactive Compounds from Polygala tenuifolia and Their Inhibitory Effects on Lipopolysaccharide-Stimulated Pro-inflammatory Cytokine Production in Bone Marrow-Derived Dendritic Cells. Plants 2020, 9, 1240. [CrossRef]

32. Vinh, L.B.; Phong, N.V.; Ali, I.; Dan, G.; Koh, Y.S.; Anh, H.L.T.; Yang, S.Y.; Kim, Y.H. Identification of potential anti-inflammatory and melanoma cytotoxic compounds from Aegiceras corniculatum. Med. Chem. Res. 2020, 29, 2020-2027. [CrossRef]

33. Ali, I.; Manzoor, Z.; Koo, J.-E.; Kim, J.-E.; Byeon, S.-H.; Yoo, E.-S.; Kang, H.-K.; Hyun, J.-W.; Lee, N.-H.; Koh, Y.-S. 3-Hydroxy-4, 7-megastigmadien-9-one, isolated from Ulva pertusa, attenuates TLR9-mediated inflammatory response by down-regulating mitogen-activated protein kinase and NF-kB pathways. Pharm. Biol. 2017, 55, 435-440. [CrossRef] [PubMed] 